\title{
Status and Risk Factors of Strongyloides stercoralis Infection in Rural Communities of Xayaburi Province, Lao PDR
}

\author{
Phasouk Senephansiri', Porntip Laummaunwai, ${ }^{2,3, *}$, Sakorn Laymanivong ${ }^{4}$, Thidarut Boonmar ${ }^{2,3}$ \\ 'National TB Reference Laboratory, National Tuberculosis Control Programme, Ministry of Health, Vientiane Capital, Lao PDR; ${ }^{2}$ Department of \\ Parasitology, Faculty of Medicine, Khon Kaen University, Khon Kaen, Thailand; ${ }^{N}$ Neglected, Zoonosis and Vector-Borne Disease Research Group, \\ Khon Kaen University, Khon Kaen, Thailand; ${ }^{4}$ Center of Malariology, Parasitology and Entomology, Ministry of Health, Vientiane Capital, Lao PDR
}

\begin{abstract}
The present study was performed to reveal the current status and risk factors of Strongyloides stercoralis infections in the villages of Kenethao district, Xayaburi Province, Lao PDR. Fecal specimens were collected and examined for S. stercoralis using Koga-agar plate culture technique. Among 516 individuals, the prevalence of S. stercoralis and hookworm infection was $44.2 \%$ and $17.1 \%$, respectively. Co-infection was detected in $13.2 \%$ of the cases. The prevalence did not significantly differ between males and females $(P=0.193)$. However, the prevalence of $S$. stercoralis infection increased significantly with age $(P=0.041)$. Of the risk factors examined, both performing farming activities $(P=0.001)$ and walking barefoot when going outside of the house $(P=0.003)$ showed significant correlations with $S$. stercoralis infections. Our results suggest that $S$. stercoralis is highly endemic in this area. The National Helminth Control Program of Lao PDR should take actions to control S. stercoralis infection. In addition, provision of health education about the benefits of wearing shoes would be important for reducing infection in the study area. Moreover, the application of high-sensitivity diagnostic approaches is needed to obtain the true impact of $S$. stercoralis infections in all rural communities in order to provide surveillance activities in Lao PDR.
\end{abstract}

Key words: Strongyloides stercoralis, risk factor, prevalence, rural area, Koga-agar plate culture

Strongyloides stercoralis infection is one of the neglected tropical diseases among the soil-transmitted helminthiases [1,2]. Endemic areas are associated with environmental conditions and poor hygiene practices that favor transmission. The infection is acquired by skin penetration of infective filariform larvae (L3). Clinical features of strongyloidiasis are variable. Light infections may be asymptomatic [3], but more than moderate infections produce dermatological (itching, skin rashes, and dermatitis), pulmonary (wheezing, cough, and pneumonitis), and gastrointestinal symptoms (diarrhea, abdominal pain, and malabsorption) [4-7]. Autoinfection leading to disseminated infection is a potentially fatal complication, especially in immunocompromised patients [8-10]. A definitive diagnosis relies on identification of larvae in stool samples. The methods used to detect $S$. stercoralis in fecal specimens include direct

\footnotetext{
- Received 3 April 2017, revised 22 June 2017, accepted 8 August 2017.

* Corresponding author (porlau@kku.ac.th)

(C) 2017, Korean Society for Parasitology and Tropical Medicine

This is an Open Access article distributed under the terms of the Creative Commons

Attribution Non-Commercial License (http://creativecommons.org/licenses/by-nc/4.0)

which permits unrestricted non-commercial use, distribution, and reproduction in any

medium, provided the original work is properly cited.
}

smears, formalin-ethyl acetate concentration (FECT), Baermann-Moraes culture, Harada-Mori culture, and Koga-agar plate (KAP) culture. Of these, KAP has been shown to be the most sensitive [11,12]. In Lao PDR, S. stercoralis and other soiltransmitted infections are highly prevalent $[13,14]$. Today, preventive drug treatments, combined with health education programs, remain the core strategy in Lao PDR. However, such measures have not reached some local communities where the prevalence of $S$. stercoralis has not been investigated.

Therefore, this study aimed to assess the prevalence of $S$. stercoralis by using KAP culture in 3 rural villages of Kenethao district where the epidemiology of this parasite has not been reported. This area was selected as the study site because it is largely an agricultural area and the lifestyle of the population provides favorable conditions for transmitting $S$. stercoralis infections. Some risk factors, such as personal hygiene practices, were also investigated. The resulting data will be valuable in planning the implementation of effective interventions in these areas. Access to treatment is urgently required in this area to prevent disseminated infection.

The study protocol was approved by the Lao National Ethics 


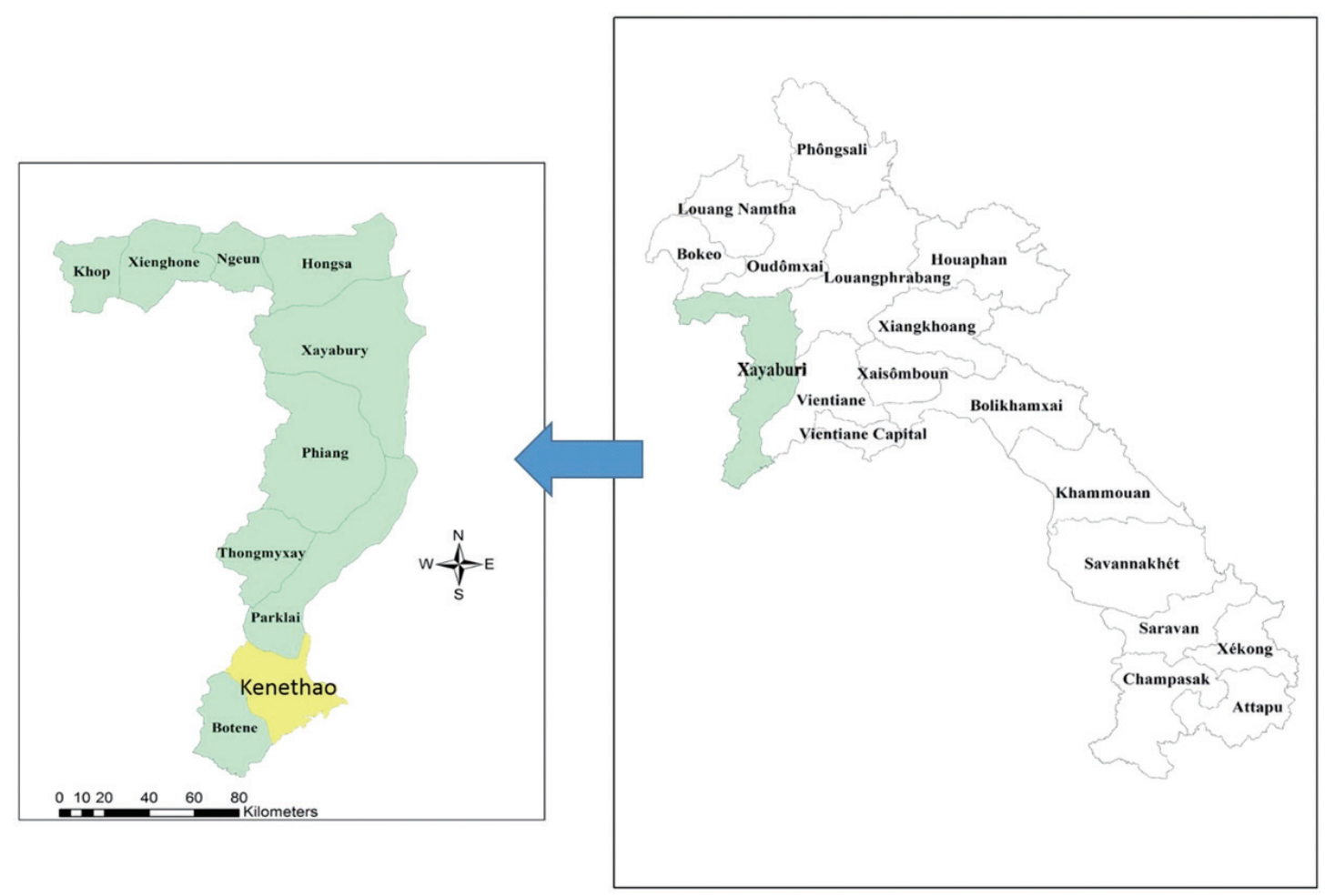

Fig. 1. Map of the surveyed area in Lao PDR.

Committee for Health Research, Ministry of Health, Laos (no. 026/2016) and by the Khon Kaen University Ethics Committee for Human Research (no. HE591490). Each participant was informed of the study methods, risks, and benefits of the process. Before enrolment, written consent was obtained from all adult participants and from parents or legal guardians of minors.

A cross-sectional study was carried out from January to February 2017, targeting the populations in 3 villages (Houay Lod, Houay Tor, and Houay Ped) in Kenethao district of Xayaburi Province, Lao PDR (Fig. 1). The study areas are located on the Thai-Laos border. The main occupations in this area are rice subsistence farming, vegetable growing, and fishing in the Hoang River and in farm irrigation canals. Between them, the villages are home to approximately 3,000 people. There is no previous information on the prevalence of $S$. stercoralis infection there. The sample size was calculated taking the latest prevalence of S. stercolaris infections estimated for Lao PDR [13]. The minimum sample size required was 368 participants with a 95\% confidence level and 5\% margin of error.

After obtaining written informed consent from participants, an individual questionnaire was administered to obtain demographic information (age, gender, and profession), and be- havioral data (personal hygiene practices and wearing of shoes). After the interview, each participant was given a pre-labeled plastic container (ID code, name, sex, age, and date) for stool sample collection. The next morning, the filled stool container was collected, and the stool samples were examined by KAP culture. Approximately $4 \mathrm{~g}$ of each fresh stool sample was placed immediately in the middle of the agar plate and closed Petri dish with parafilm. All plates were then transported by car for $3 \mathrm{hr}$ from the study area to the laboratory room of Department of Parasitology, Faculty of Medicine at Khon Kaen University where all plates were incubated at $25^{\circ} \mathrm{C}$ for 3 days. Plates were then visually examined for the presence of tracks of larvae. To differentiate between $S$. stercoralis and hookworm larvae, the plates were then rinsed with $10 \%$ formalin. The eluent was centrifuged, and the sediment was examined using a microscope for the presence of larvae. Based on the morphology, larvae were identified by the presence of genital primordium, size of buccal cavity (L1, L2), and the presence of notched tail-end (L3) as either S. stercoralis or hookworm larvae.

The prevalence of $S$. stercoralis was stratified according to sociodemographic data and reported by descriptive statistics. The chi-square test $\left(\chi^{2}\right)$ was used to determine whether there was a 
Table 1. Prevalences of Strongyloides stercoralis and hookworm infection using Koga-agar plate culture technique $(n=516)$

\begin{tabular}{lcc}
\hline Type of infection & S. stercoralis positive (\%) & Hookworm positive (\%) \\
\hline Single & $160(31.0)$ & $20(3.9)$ \\
Double & $68(13.2)$ & $68(13.2)$ \\
Total positive & $228(44.2)$ & $88(17.1)$ \\
\hline
\end{tabular}

statistically significant difference between the parasite-infected and uninfected groups. It was also used to test other variable factors. The level of statistical significance was set at $P$-value of less than 0.05 .

A total of 516 individual participated in this study. The age ranged between 1 and 88 years, with a median age of 44 years. In this cohort, 211 (40.9\%) and 305 (59.1\%) were males and females, respectively. Most of the participants were farmers 418 (81\%), and 98 (19\%) were students. Most participants were more than 46 years old. The prevalences of $S$. stercoralis and hookworms detected by KAP culture were 228 (44.2\%) and 88 (17.1\%), respectively. Of those infected with S. stercoralis, 13.2\% were co-infected with hookworms (Table 1).

The results of association of risk factors with $S$. stercoralis are presented in Table 2. Prevalences did not differ significantly between males and females $(P=0.193)$. However, the prevalence of $S$. stercoralis infection increased significantly with age $(P=0.041)$. Farmers showed a significant correlation with $S$. stercoralis infection $(P=0.001)$. The most important risk factor for $S$. stercoralis infection was failure to wear shoes when going outside of the house $(P=0.003)$. No association was found between $S$. sterocoralis infection and the frequency of hand washing $(P=0.165)$.

Strongyloidiasis is one of the neglected tropical diseases [2]. The highest prevalences are found in poor countries with a tropical climate, conditions favorable for transmission of the parasite [16]. Furthermore, low socioeconomic status and lowhygiene living conditions of the rural population are strongly associated with S. stercoralis infections. In Southeast Asia, a recent work in Cambodia reported a very high infection rate of $21 \%$ in Takeo Province [15]. In Lao PDR, there have been few studies on S. stercoralis infection, and data usually come from studies on other soil-transmitted helminths (STH) and/or food-borne trematodes [14]. One of such studies has reported a $10.3 \%$ prevalence of $S$. stercoralis infection, but the diagnostic method is low in sensitivity, which was mostly formalin-ethyl acetate concentration method. To our knowledge, this is the first community-based report from this region. Recent surveys
Table 2. Correlation between Strongyloides stercoralis infection and sociodemographic characteristics of the participants

\begin{tabular}{lrrrr}
\hline Characteristics & $\begin{array}{c}\text { No- } \\
\text { infection } \\
(\%)\end{array}$ & $\begin{array}{c}\text { Infection } \\
(\%)\end{array}$ & $\chi^{2}$ & $P$-value \\
\hline Gender & & & & \\
$\quad$ Male & 125 & $86(40.7)$ & & \\
$\quad$ Female & 163 & $142(46.5)$ & 1.69 & 0.193 \\
Age group (year) & & & & \\
$1-5$ & 12 & $3(20.0)$ & & \\
$6-15$ & 27 & $16(37.2)$ & & \\
$16-25$ & 35 & $19(35.2)$ & & \\
$26-35$ & 40 & $43(51.8)$ & & \\
$36-45$ & 51 & $54(51.4)$ & & \\
$46-55$ & 59 & $55(48.2)$ & & \\
$>55$ & 64 & $38(37.3)$ & 13.12 & $0.041^{*}$ \\
Occupation & & & & \\
$\quad$ Farmer & 208 & $210(50.2)$ & & \\
$\quad$ Student & 80 & $18(22.5)$ & 32.7 & $0.001^{*}$ \\
Personal hygiene & & & & \\
Wash hands after toilet & & & & \\
$\quad$ Regularly & 53 & $32(37.6)$ & & \\
$\quad$ Irregularly & 235 & $196(45.4)$ & 1.74 & 0.187 \\
Wear shoes when go outside & & & & \\
Regularly & 37 & $12(24.4)$ & & \\
Irregularly & 251 & $216(46.3)$ & 8.5 & $0.003^{*}$ \\
\hline
\end{tabular}

on S. stercoralis infection in southern Lao PDR reported a prevalence of $41 \%$ on Mekong river islands [13]. Here, we aimed to document the prevalence of $S$. stercoralis infection and risk factors in the villages in northern Lao PDR.

As far as we know, the most sensitive method for S. stercoralis diagnosis is KAP culture [11,12]. We used this method on a single stool sample from each participant and found a prevalence of $44.2 \%$. Of the risk factors examined, being a farmer $(P=0.001)$ and failure to wear shoes outside the house $(P=0.003)$ showed a significant correlation with $S$. stercoralis infection. Previous reports have also showed that high prevalences of $S$. stercoralis infection were correlated with working in farms and failure to wear shoes [13]. We did not find any association between $S$. stercoralis infection and the frequency of hand washing. S. stercoralis infection is therefore probably not acquired by the fecal-oral route.

In our study, the prevalence of S. stercoralis infections in older people was significantly higher than in younger people $(P=0.041)$. This may be because older people have more activities in the farm than younger people. The results also showed that children under the age of 6 years had also been infected with $S$. stercoralis. These children actually do not carry out farming activities. Therefore, the transmission of S. stercoralis must happen at home. This finding is similar to the one 
reported in a Cambodian study [16]. To our knowledge, animals, such as dogs, can act as reservoir hosts for $S$. stercoralis. In order to reach a conclusion about human-animal transmission, household dogs in these areas should be examined for $S$. stercoralis larval infections.

The infection prevalence in this study showed higher than the recent reports from Cambodia [17], Thailand [18], and China [19]. We may have underestimated the prevalence because only a single stool sample was examined from each participant. To obtain the true prevalence, several stool samples should be considered. Given the fact that hookworms and $S$. stercoralis have the same transmission route of infection, we noted a rather low prevalence of hookworms. Perhaps KAP culture is not a suitable method to diagnose hookworm infections, especially in light infections. Formalin-ether concentration technique, therefore, should be considered to diagnose the other soil-transmitted helminths. Our research has confirmed that walking barefoot outside the house and while carrying out farming activities are the risk factors for $S$. stercoralis infection. In addition, another important risk factor is a low level of community awareness about worm infections. In order to provide an effective control, the local communities should be furnished with good knowledge about worms and how to improve personal hygiene, such as wearing shoes when coming into contact with soil. As mentioned above, most studies have been based on other STH infections, and only a few papers have reported the prevalence of $S$. sterocoralis larvae. Therefore, the results have mostly been based on the use of low-sensitivity diagnostic methods, and the prevalence has been underreported. In order to carry out active surveillance, high-sensitivity diagnostic methods should be incorporated in order to comprehend the true burden of infections in this country.

In conclusion, $S$. stercoralis infection is highly endemic in the village of the Kenethao district, Xayaburi Province, northern Loa PDR. The important risk factors for S. stercoralis infections are farming activities and walking without shoes when going outside of the house. The results of this study should be noted by the National Helminth Control Program. Health education programs about the risk of infection and how to prevent infection are critical in this area. Promotion of hygienic practices is essential to assure long term health benefits. To carry out active surveillance, the researchers suggest using the high-sensitivity diagnostic methods to reveal the true impact that $S$. stercoralis infection has had on all rural communities in Lao PDR.

\section{ACKNOWLEDGMENTS}

This work was supported by a grant from Khon Kaen University and the Higher Education Research Promotion, Thailand. We also wish to thank Faculty of Medicine, Department of Parasitology, the research group of Neglected, Zoonosis and Vector-Borne Disease, Khon Kaen University, Khon Kaen, Thailand for their assistance.

\section{CONFLICT OF INTEREST}

We have no conflict of interest related to this work.

\section{REFERENCES}

1. Hotez PJ, Molyneux DH, Fenwick A, Ottesen E, Ehrlich Sachs S, Sachs JD. Incorporating a rapid-impact package for neglected tropical diseases with programs for HIV/AIDS, tuberculosis, and malaria. PLoS Med 2006; 3: e102.

2. Olsen A, van Lieshout L, Marti H, Polderman T, Polman K, Steinmann P, Stothard R, Thybo S, Verweij JJ, Magnussen P. Strongyloidiasis-the most neglected of the neglected tropical diseases? Trans R Soc Trop Med Hyg 2009; 103: 967-972.

3. Foreman EB, Abraham PJ, Garland JL. Not your typical Strongyloides infection: a literature review and case study. South Med J 2006; 99: 847-852.

4. Ly MN, Bethel SL, Usmani AS, Lambert DR. Cutaneous Strongyloides stercoralis infection: an unusual presentation. J Am Acad Dermatol 2003; 49 (suppl): 157-160.

5. Vadlamudi RS, Chi DS, Krishnaswamy G. Intestinal strongyloidiasis and hyperinfection syndrome. Clin Mol Allergy 2006; 4: 8.

6. Koczka CP, Hindy P, Goodman A, Gress F. Strongyloidiasis: a diagnosis more common than we think. Eur J Gastroenterol Hepatol 2012; 24: 860862.

7. Khieu V, Srey S, Schär F, Muth S, Marti H, Odermatt P. Strongyloides stercoralis is a cause of abdominal pain, diarrhea and urticaria in rural Cambodia. BMC Res Notes 2013; 6: 200.

8. Marcos LA, Terashima A, Dupont HL, GotuzzoE. Strongyloides hyperinfection syndrome: an emerging global infectious disease. Trans R Soc Trop Med Hyg 2008; 102: 314-318.

9. Vadlamudi RS, Chi DS, Krishnaswamy G. Intestinal strongyloidiasis and hyperinfection syndrome. Clin Mol Allergy 2006; 4: 8.

10. Basile A, Simzar S, Bentow J, Antelo F, Shitabata P, Peng SK, Craft N. Disseminated Strongyloides stercoralis: hyperinfection during medical immunosuppression. J Am Acad Dermatol 2010; 63: 896-902.

11. Jongwutiwes S, Charoenkorn M, Sitthichareonchai P, Akaraborvorn P, Putaporntip C. Increased sensitivity of routine laboratory detection of Strongyloides stercoralis and hookworm by agar-plate culture. Trans R Soc Trop Med Hyg 1999; 93: 398-400. 
12. Sato Y, Kobayashi J, Toma H, Shiroma Y. Efficacy of stool examination for detection of Strongyloides infection. Am J Trop Med Hyg 1995; 53: 248-250.

13. Vonghachack Y, Sayasone S, Bouakhasith D, Taisayavong K, Akkavong K, Odermatt P. Epidemiology of Strongyloides stercoralis on Mekong islands in southern Laos. Acta Trop 2015; 141: 289294.

14. Sayasone S, Vonghajack Y, Vanmany M, Rasphone O, Tesana S, Utzinger J, Akkhavong K, Odermatt P. Diversity of human intestinal helminthiasis in Lao PDR. Trans R Soc Trop Med Hyg 2009; 103: 247-254.

15. Khieu V, Schiar F, Marti H, Bless PJ, Char MC, Muth S, Odermatt P. Prevalence and risk factors of Strongyloides stercoralis in Takeo Province, Cambodia. Parasit Vector 2014; 7: 221.

16. Khieu V, Schär F, Forrer A, Hattendorf J, Marti H, Duong S, Vounatsou P, Muth S, Odermatt P. High prevalence and spatial dis- tribution of Strongyloides stercoralis in rural Cambodia. PLoS Negl Trop Dis 2014; 8: e2854.

17. Schär F, Inpankaew T, Traub RJ, Khieu V, Dalsgaard A, Chimnoi W, Chhoun C, Sok D, Marti H, Muth S, Odermatt P. The prevalence and diversity of intestinal parasitic infections in humans and domestic animals in a rural Cambodian village. Parasitol Int 2014; 63: 597-603.

18. Jongsuksuntigul P, Intapan PM, Wongsaroj T, Nilpan S, Singthong S, Veerakul S, Maleewong, W. Prevalence of Strongyloides stercoralis infection in northeastern Thailand (agar plate culture detection). J Med Assoc Thai 2003; 86: 737-741.

19. Steinmann P, Zhou XN, Du ZW., Jiang JY, Wang LB, Wang XZ, Li $\mathrm{LH}$, Marti H, Utzinger J. Occurrence of Strongyloides stercoralis in Yunnan Province, China, and comparison of diagnostic methods. PLoS Negl Trop Dis 2007; 1: e75. 
